Article

\title{
Synthesis and Cytotoxic Activity of Chiral Sulfonamides Based on the 2-Azabicycloalkane Skeleton
}

\author{
Mahzeiar Samadaei ${ }^{1}\left(\mathbb{D}\right.$, Matthias Pinter $\left.^{1}{ }^{(}\right)$, Daniel Senfter ${ }^{1}\left(\mathbb{D}\right.$, Sibylle Madlener ${ }^{1}{ }^{(D}$, \\ Nataliya Rohr-Udilova ${ }^{1, * \mathbb{D}}$, Dominika Iwan ${ }^{2} \mathbb{D}$, Karolina Kamińska ${ }^{2} \mathbb{D}$, \\ Elżbieta Wojaczyńska ${ }^{2, *(D)}$, Jacek Wojaczyński ${ }^{3}$ (D) and Andrzej Kochel ${ }^{3}$ (D) \\ 1 Department of Internal Medicine III, Medical University of Vienna, AKH Vienna Währinger Gürtel 18-20, \\ 1090 Vienna, Austria; mahzeiar.samadaei@meduniwien.ac.at (M.S.); matthias.pinter@meduniwien.ac.at (M.P.); \\ daniel.senfter@meduniwien.ac.at (D.S.); sibylle.madlener@meduniwien.ac.at (S.M.) \\ 2 Faculty of Chemistry, Wrocław University of Science and Technology, Wybrzeże Wyspiańskiego 27, \\ 50-370 Wrocław, Poland; dominika.iwan@pwr.edu.pl (D.I.); karolina.kaminska@pwr.edu.pl (K.K.) \\ 3 Faculty of Chemistry, University of Wrocław, F. Joliot-Curie St. 14, 50-383 Wrocław, Poland; \\ jacek.wojaczynski@chem.uni.wroc.pl (J.W.); andrzej.kochel@chem.uni.wroc.pl (A.K.) \\ * Correspondence: nataliya.rohr-udilova@meduniwien.ac.at (N.R.-U.); \\ elzbieta.wojaczynska@pwr.edu.pl (E.W.); Tel.: +43-14040047230 (N.R.-U.); +48-713202410 (E.W.)
}

Received: 25 March 2020; Accepted: 11 May 2020; Published: 18 May 2020

\begin{abstract}
A series of chiral sulfonamides containing the 2-azabicycloalkane scaffold were prepared from $a z a$-Diels-Alder cycloadducts through their conversion to amines based on 2-azanorbornane or the bridged azepane skeleton, followed by the reaction with sulfonyl chlorides. The cytotoxic activity of the obtained bicyclic derivatives was evaluated using human hepatocellular carcinoma (HCC), medulloblastoma (MB), and glioblastoma (GBM) cell lines. Chosen compounds were shown to notably reduce cell viability as compared to nonmalignant cells.
\end{abstract}

Keywords: 2-azabicycloalkane; chiral sulfonamide; cytotoxic activity

\section{Introduction}

A continuous demand for novel, potent, and selective anticancer drugs has led to the development of various classes of therapeutics. Among them, sulfonamides have attracted considerable attention due to their high and multidirectional activity, and are used or tested as pharmaceutical agents, possessing antibacterial, antiviral, anticancer, antimalarial, diuretic, hypoglycemic, anticonvulsant, antirheumatic, and antithyroid properties [1-5]. In addition to functional groups, certain characteristic structural motifs are also associated with impressive biological activity. For example, the biphenyl moiety is present in numerous derivatives that have been tested in antiproliferative studies [6-8]. The trifluoromethyl group is also regarded as a valuable pharmacophore [9], which is found in marketed drugs (e.g., nonsteroidal antiandrogen flutamide) and newly developed derivatives [10]. Additionally, 2-azanorbornane (2-azabicyclo[2.2.1]heptane) 1 (Figure 1), an intrinsically chiral compound with a stable bicyclic skeleton, has been recognized as a versatile scaffold for asymmetric synthesis and a precursor or a component of molecules exhibiting biological activity [11]. This system can be prepared via the stereoselective $a z a$-Diels-Alder reaction of chiral imines and cyclopentadiene in both enantiomeric forms, even in large quantities (grams or kilograms) [12-17]. Derivatives of 2-azanorbornane have already been applied in various enantioselective transformations $[11,18]$. An expanded bicyclic system, namely 2-azabicyclo[3.2.1]octane, can be prepared in a stereoselective manner from 2-aznanorbornylmethanols under nucleophilic substitution reaction conditions [19]. Using this approach, isomeric amines based on the bridged piperidine (compound 2, Figure 1) or 
azepane (isomer 3, Figure 1) were prepared [20,21]. We used these amines and their epimers for the construction of bifunctional catalysts [22]. Monomeric and dimeric derivatives modified with amino functions were also prepared and were found to inhibit the growth of selected tumor cell lines [7].

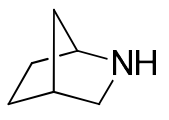

1

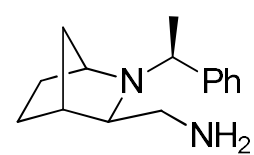

2

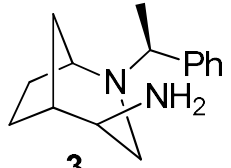

3

Figure 1. The 2-azanorbornane (1) and isomeric amines containing bicyclic skeletons $(2,3)$.

The promising results of our study on the biological activity of amines bearing chiral azabicyclic skeletons prompted us to prepare a series of corresponding sulfonamides. Based on literature reports, we were convinced that introduction of the sulfonamide function, also with biphenyl substituents, should result in the enhancement of cytotoxicity and bioavailability. For example, combinations of sulfonamide and thiourea derivatives produced promising anticancer agents in the study by Ghorab et al. [2], while the methanesulfonamide analogue of cryptopleurine exhibited improved bioavailability and antitumor activity, as reported by Kwon et al. [4]. In this article, we present the synthesis of new bicyclic derivatives and the study of their interaction with selected human tumor cell lines and nonmalignant primary cells. We believed that molecules that contain both sulfonamide and biphenyl or trifluoromethyl moieties could lead to new hybrid architectures with improved biological profiles.

\section{Materials and Methods}

\subsection{Instrumentation}

Melting points were determined on the Schmelzpunkt Bestimmer Apotec melting point apparatus (WEPA Apothekenbedarf GmbH \& Co. KG., Hillscheid, Germany) using the standard open capillary. ${ }^{1} \mathrm{H}$ and ${ }^{13} \mathrm{C}$ NMR spectra were collected on Jeol 400yh (Joel Ltd., Tokyo, Japan), Bruker Avance III 500, and Bruker Avance II 600 instruments (Bruker, Billerica, MA, USA). NMR spectra recorded in $\mathrm{CDCl}_{3}$ were referenced to the respective residual ${ }^{1} \mathrm{H}$ or ${ }^{13} \mathrm{C}$ signals of the solvent; chemical shifts are expressed in ppm, and coupling constants in Hz. Infrared spectra $\left(4000-400 \mathrm{~cm}^{-1}\right)$ were collected on a Perkin Elmer 2000 FTIR spectrometer (PerkinElmer, Waltham, MA, USA). High-resolution mass spectra were collected using electrospray ionization on a Waters LCT Premier XE TOF instrument (Waters Corporation, Milford, MA, USA). Optical rotations were measured using an Model AA-5 automatic polarimeter (Optical Activity, Ltd., Ramsey, UK); $[\alpha]_{D}$ values are given in $10^{-1} \mathrm{deg} \mathrm{\textrm {cm } ^ { 2 }}$ $\mathrm{g}^{-1}$. Chromatographic separations were performed on silica gel 60 (70-230 mesh). Thin-layer chromatography was carried out using silica gel 60 precoated plates.

X-ray diffraction data for monocrystals were collected on an Xcalibur Ruby diffractometer [23] with $\mathrm{MoK}_{\alpha}$ radiation at 80(2) K. The Cambridge Crystallographic Data Centre (CCDC) reference numbers for 12a and 12d: CCDC 1992131 (12a) and 1992390 (12d) (Supplementary data available from CCDC, 12 Union Road, Cambridge CB2, 1EZ, UK on request). The crystal structures were solved with direct methods in SHELXT and refined using the full-matrix method in SHELXL [24]. H atoms bonded to $C$ atoms were generated using HFIX instruction with $\mathrm{U}_{\text {eq }}=1.2-1.5 \mathrm{U}_{\text {eq }}$ (parent $\mathrm{C}$ atom). Basic crystallographic data are presented in Supplementary Table S1.

\subsection{Preparation of Starting Compounds}

The bicyclic amines, $(1 S, 3 R, 4 R)-2-[(S)$-1-phenylethyl]-3-aminemethyl-2- azabicyclo[2.2.1]heptane 2 and (1S,4S,5R)-2-[(S)-1-phenylethyl]-4-amine-2- azabicyclo[3.2.1] octane 3, were prepared as described previously $[20,21]$. The synthesis of enantiopure 2-azanorbornane amine derivatives containing two bicyclic units 8 and $\mathbf{9}$ was also reported by our group [21]. 


\subsection{General Procedure for Sulfonamide Synthesis}

The appropriate sulfonyl chloride $(1.0 \mathrm{mmol})$ was added to a solution of primary amine 2 or 3 $(0.23 \mathrm{~g}, 1.0 \mathrm{mmol})$ and powdered potassium hydroxide $(0.10 \mathrm{~g}, 1.8 \mathrm{mmol})$ in a dry dichloromethane $(15.0 \mathrm{~mL})$, which was stirred at room temperature. After $24 \mathrm{~h}$, the resulting reaction mixture was poured over brine and extracted with dichloromethane. The organic phases were dried over $\mathrm{Na}_{2} \mathrm{SO}_{4}$, filtered through the Celite ${ }^{\circledR}$, washed with dichloromethane, and evaporated under vacuum. The resulting residue was purified by column chromatography on silica (eluent: ethyl acetate/ $n$-hexane 1:1 v/v), yielding sulfonamide $\mathbf{1 0}$ (from amine $\mathbf{2}$ ) or $\mathbf{1 1}$ (from amine $\mathbf{3}$ ). An analogous procedure was applied to the synthesis of compound 13a from amine $9(0.44 \mathrm{~g}, 1.0 \mathrm{mmol})$ and biphenyl-4-sulfonyl chloride $(0.25 \mathrm{~g}, 1.0 \mathrm{mmol})$; the $n$-hexane/ethyl acetate $(3 / 1 \mathrm{v} / \mathrm{v})$ mixture was used for elution of the product. For synthesis of compounds bearing two sulfonamide functions, 12, bisamine 8 ( $0.48 \mathrm{~g}, 1.0 \mathrm{mmol})$ was reacted with $2.0 \mathrm{mmol}$ of the appropriate sulfonyl chloride; final products were eluted with $n$-hexane/ethyl acetate (3/1 v/v for $12 \mathrm{a}, 1 / 1 \mathrm{v} / \mathrm{v}$ for the remaining derivatives). The physicochemical characterization of all newly obtained compounds (including copies of ${ }^{1} \mathrm{H}$ and ${ }^{13} \mathrm{C}$ NMR spectra, and $\mathrm{X}$-ray structures of compounds 12a and 12d) can be found in the Supplementary Materials.

\subsection{Cell Lines and Culture Cconditions}

The human hepatocellular carcinoma (HCC) cell line HUH7 was purchased from ATCC (LGC standards GmbH, Wesel, Germany). The Austrian human HCC cell line AKH12 has been well characterized [21-25] and was kindly provided by Prof. Bettina Grasl-Kraupp. HUH7 cells were cultured in Dulbecco's modified Eagle's medium (Thermo Fisher Scientific, Waltham, MA, USA) containing 10\% heat-inactivated fetal bovine serum (FBS) (Sigma-Aldrich, St. Louis, MO, USA), $1 \%$ penicillin-streptomycin $(10,000 \mathrm{U} / \mathrm{mL}$ ) (Thermo Fisher Scientific, Waltham, MA, USA), and 1\% minimum essential medium nonessential amino acids (100x) (Thermo Fisher Scientific, Waltham, MA, USA). AKH12 cells were cultured in RPMI1640 medium (Sigma-Aldrich, St. Louis, MO, USA) containing 10\% heat-inactivated FBS. DAOY and D283Med (short D283) medulloblastoma (MB) cells were purchased from ATCC (LGC standards GmbH, Wesel, Germany). D425Med (short D425) and UW228-2 were provided by Thomas Ströbel from the Institute of Neurology Medical University of Vienna. The cells were cultured in Dulbecco's modified Eagle's medium (Sigma-Aldrich, St. Louis, MO, USA) containing 10\% FBS (Sigma-Aldrich, St. Louis, MO, USA), 2\% L-Glutamine (Sigma-Aldrich, St. Louis, MO, USA), and 0.2\% Normocin (Sigma-Aldrich, St. Louis, MO, USA). U-251 MG (short U251) glioblastoma (GBM) cell line was purchased from Sigma-Aldrich and cultured in Dulbecco's modified Eagle's medium (Sigma-Aldrich, St. Louis, MO, USA) containing 10\% FBS (Sigma-Aldrich, St. Louis, MO, USA), 2\% L-Glutamine (Sigma-Aldrich, St. Louis, MO, USA), and 0.2\% Normocin (Sigma-Aldrich, St. Louis, Missouri, USA). Human umbilical vein endothelial cells (HUVECs) were provided by Brigitte Winter from the Department of Surgery Medical University of Vienna and were grown in endothelial cell growth medium-2 BulletKitTM (Lonza, Basel, Switzerland) under standard tissue culture conditions. All cells were incubated at $37^{\circ} \mathrm{C}$ in a $5 \% \mathrm{CO}_{2}$ atmosphere and regularly checked for mycoplasma contamination.

\subsection{Cell Viability Assay (Adherent Cell Lines)}

Cell viability was determined using a neutral red assay, as previously described [26]. The cells were placed in 24 -well plates and grown to reach $70-80 \%$ confluency prior to treatment. After treatment for $24 \mathrm{~h}$, cells were incubated with neutral red at a concentration of $50 \mu \mathrm{g} / \mathrm{mL}$ in serum-free medium for $2 \mathrm{~h}$ at $37^{\circ} \mathrm{C}$. Cells were then washed $2 \mathrm{x}$ and incubated with $1 \%$ acetic acid in $70 \%$ ethanol. The dye concentration was measured photometrically at $562 \mathrm{~nm}$. The percentage of survival was calculated considering DMSO-treated (indicated as $0 \mu \mathrm{M}$ concentration) cells as 100\% control. The final DMSO concentration in media did not exceed $0.2 \%$. 
$\mathrm{LD}_{50}$ was defined as the amount of a toxic agent required to eliminate $50 \%$ of the cell population. The $\mathrm{LD}_{50}$ was calculated in each experiment from the respective dose-response curve. All experiments were performed in triplicate wells.

\subsection{Cell Viability Assay (Suspension Cell Line)}

One day before treatment, $2 \times 10^{4}$ of D425Med or HUVEC cells were seeded into 24-well plates and incubated at $37^{\circ} \mathrm{C}$ in a humidified atmosphere containing $5 \% \mathrm{CO}_{2}$. The cells were treated with different compounds for $24 \mathrm{~h}$. A MTT (3-(4,5-dimethylthiazol-2-yl)-2,5-diphenyltetrazolium bromide) assay using the CellTiter Blue reagent (Promega, Fitchburg, Wisconsin, USA) was performed according to the manufacturer's protocol. Experiments were performed in triplicate and repeated three times. The percentage of survival was calculated as the ratio using DMSO-treated (indicated as $0 \mu \mathrm{M}$ concentration) cells as $100 \%$ control. The final DMSO concentration in media did not exceed $0.2 \%$.

\subsection{Determination of Lactate Dehydrogenase (LDH)}

LDH release into culture media was measured by a cytotoxicity detection kit from Roche Diagnostics, according to the manufacturer's instruction. LDH-positive controls or 100\% lysed cells were generated in each cellular experiment by addition of Triton X100. Additionally, 0.2\% DMSO was used as the vehicle control.

\section{Results and Discussion}

\subsection{Preparation of Compounds}

Enantiopure isomeric amines based on bicyclic skeletons of 2-azabicyclo[2.2.1]heptane 2 and 2-azabicyclo[3.2.1] octane 3 were prepared from $(1 S, 3 R, 4 R)-2-[(S)-1$-phenylethyl]-3- hydroxymethyl-2azabicyclo[2.2.1]heptane 4, as previously described [19,21]. Nucleophilic substitution of the hydroxyl group of alcohol 4 with azide resulted in ring expansion, exclusively giving one stereoisomeric product 7, which was then reduced with triphenylphosphine to yield amine 3 (Scheme 1). In turn, amine 2, containing a preserved bicyclic system, was obtained using a three-step route involving Swern oxidation of alcohol 4, conversion of the resulting aldehyde to oxime 6, and its reduction. Amines containing two bicyclic fragments 8 and 9 were also reported in our previous paper [21]; their preparation included reaction of aldehyde 5 with ethylenediamine or amine 2 , respectively, followed by reduction of the obtained imines with sodium borohydride (Scheme 1).

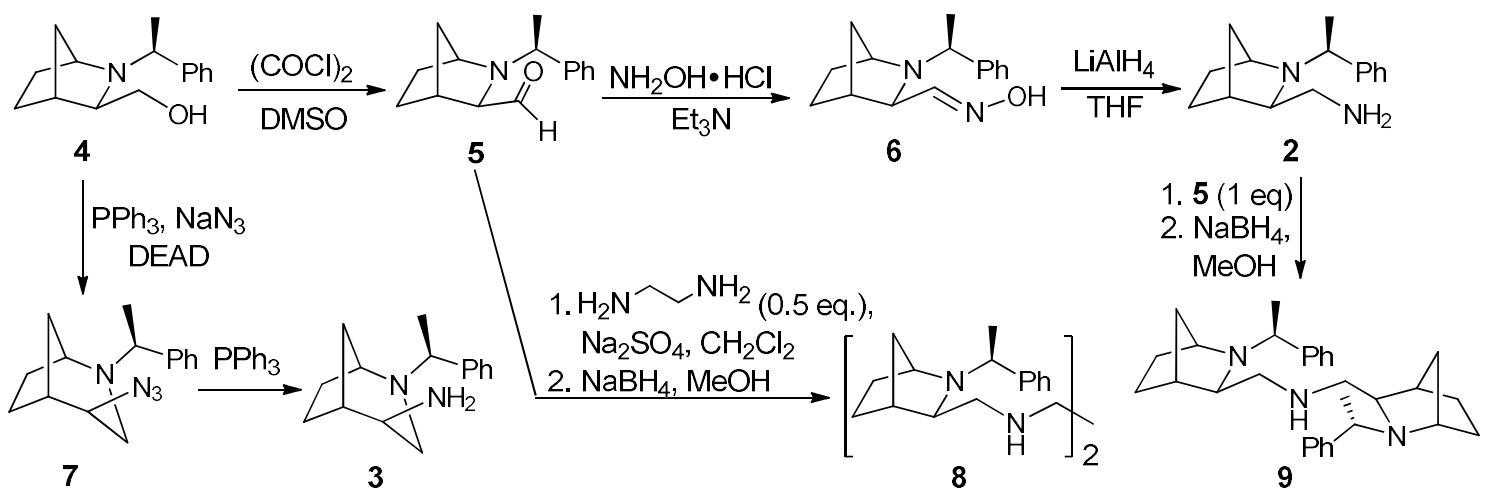

Scheme 1. Synthesis of amines $2,3,8$, and 9.

Amines 2, 3, 8, and 9 were converted into a series of sulfonamides. To this end, they were reacted with various sulfonyl chlorides in dichloromethane solution in the presence of powdered potassium hydroxide (Scheme 2). After chromatographic purification, they were obtained as crystalline solids or oils at $30-85 \%$ yield. Their structures were confirmed by spectroscopic methods (FTIR, ${ }^{1} \mathrm{H}$, and ${ }^{13} \mathrm{C}$ NMR) and high-resolution mass spectrometry (data available in Supplementary Materials). 
In this way, enantiomerically pure derivatives $\mathbf{1 0}$ and 11, differing in the size of the bicyclic skeleton and the distance of sulfonamide function from the chiral scaffold, were obtained together with compounds possessing two 2-azanorbornane subunits and one (13) or two (12) sulfonamide fragments. The introduced substituents included biphenyl (10a-13a), substituted biphenyl (10b-10e, 11e, 12b, and 12d), trifluoromethylated phenyls (10f-g, 11f-g), chiral camphoryl moiety $(\mathbf{1 0 h}, \mathbf{1 1 h})$, and acetamide derivative (12i, 13i). The choice of these groups was substantiated by their presence in various drugs and therapeutics. Besides full spectroscopic characterization, structures of derivatives 12a and 12d were additionally confirmed by X-ray crystallography (structures shown in Supplementary Materials). We further investigated the impact of the sulfonamide structure on their cytotoxicity.
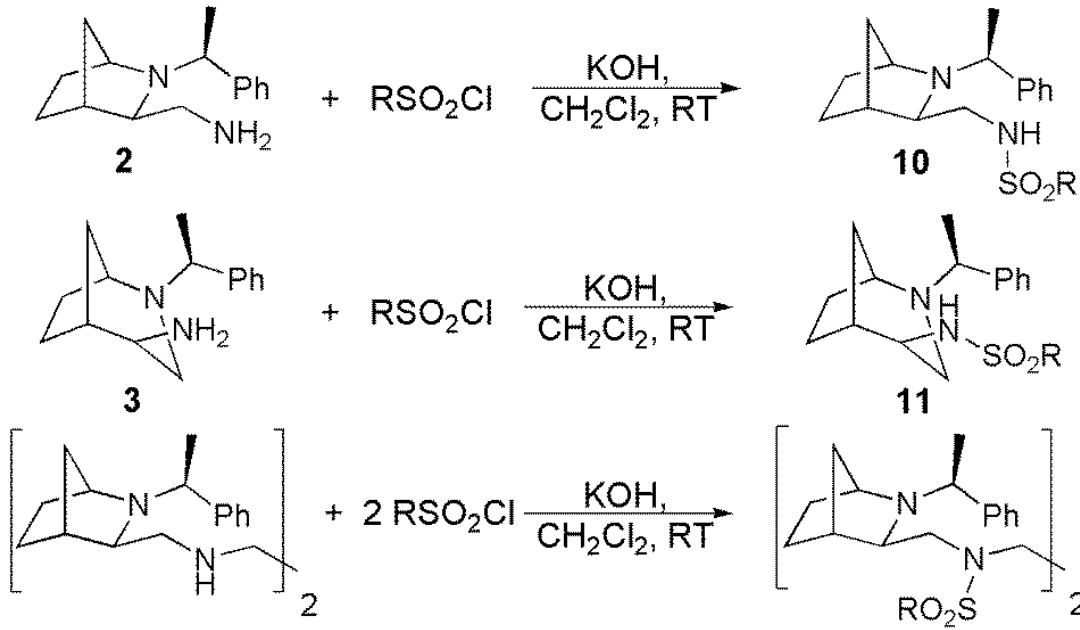

8

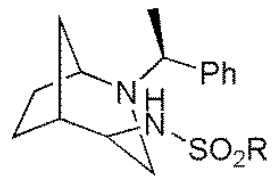

11

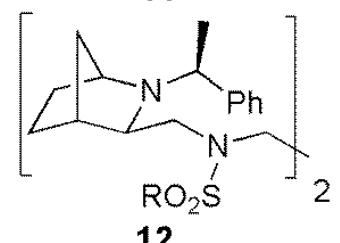

12
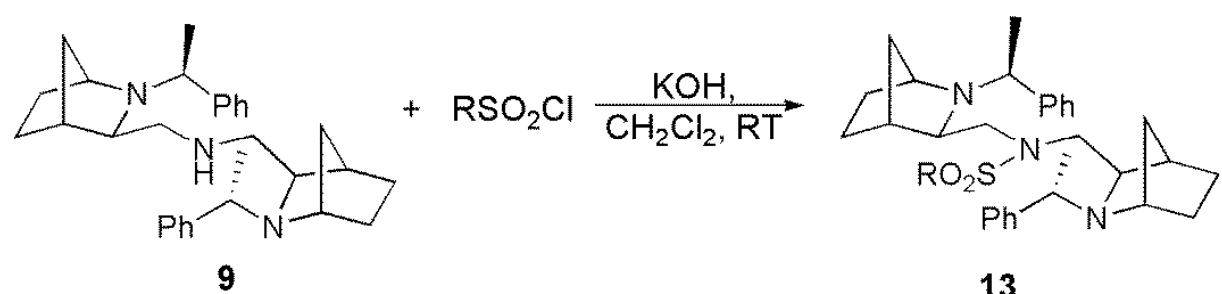

13

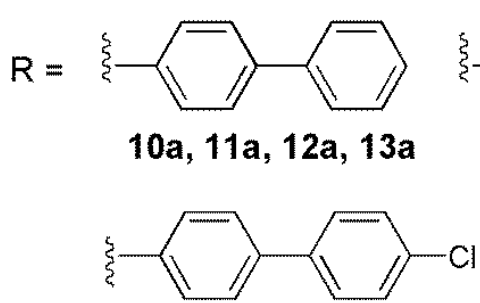

12d

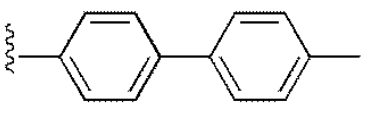

$10 \mathrm{~b}, 12 \mathrm{~b}$

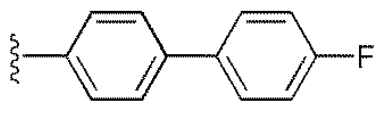

$10 \mathrm{c}$<smiles>FC(F)(F)c1cc(I)cc(C(F)(F)F)c1</smiles>

$10 \mathrm{~g}, 11 \mathrm{~g}$<smiles>COc1ccc(-c2ccc(I)cc2)cc1</smiles>
$10 \mathrm{e}, 11 \mathrm{e}$<smiles>FC(F)(F)c1ccc(C(F)(F)F)cc1</smiles>

10f, 11f<smiles>CCCC12CCC(CC1=O)C2(C)C</smiles>

$10 \mathrm{~h}, 11 \mathrm{~h}$<smiles>[Y]c1ccc(NC(C)=O)cc1</smiles>

$12 i$

Scheme 2. Synthesis of sulfonamides 10-13.

\subsection{Primary Evaluation of the Anticancer Activity of Sulfonamide Compounds}

All tested compounds were dissolved in dimethyl sulfoxide (DMSO). The solubility of compounds 12b, 12d, 8, and 9 was not sufficient for our in vitro study. In the first screening, compounds that reduced cell viability by more than $50 \%$ at $50 \mu \mathrm{M}$ after $24 \mathrm{~h}$ were considered as positive hints and were eligible 
for lactate dehydrogenase (LDH) cytotoxicity assay. To assess the anticancer activity of compounds, we tested human hepatocellular carcinoma (HCC), medulloblastoma (MB), and glioblastoma (GBM) cell lines. Further, to compare the effects of selected compounds on nonmalignant primary cells, we used primary human umbilical vein endothelial cells (HUVEC).

\subsection{Sulfonamides and HCC Cell Lines}

HCC accounts for a vast majority of liver cancer and is among the leading causes of cancer-related mortality [27]. HCC has been considered as a highly chemoresistant cancer, and hence is a good candidate for our study. The introduced $50 \mu \mathrm{M}$ concentration of $10 \mathrm{a}, \mathbf{1 0 b}, \mathbf{1 0 c}, \mathbf{1 0 e}, \mathbf{1 0 f}, \mathbf{1 0 g}, \mathbf{1 1 a}, 11 \mathrm{e}$, 11g, 12i, and 13a compounds reduced cell viability below LD 50 in HUH7 and AKH12 cell lines (Table 1; Figures S1A and S3A available in Supplementary Materials). 50 $\mathrm{M}$ concentration of 11f, however, only diminishes viability of HUH7 cells by more than $50 \%$. The cytotoxicity of mentioned compounds was measured by the LDH release in a dose-dependent manner (Supplementary Figures S1B and S3B). The cytotoxicity was compared between HCC and HUVEC cells. Our results showed no significant differences of sulfonamide cytotoxicity in HCC cell as compared to HUVEC cells (Supplementary Figures S2 and S4-data available in Supplementary Materials). LD $_{50}$ values for the above compounds tested in HUH7, AKH12, and HUVEC cells are summarized in Table 1.

Table 1. $\mathrm{LD}_{50}$ values for specified sulfonamides tested in Huh7, AKH12, DAOY, UW228-2, D283 and U251 tumor cell lines, as well as in human umbilical vein endothelial cells (HUVEC) cells.

\begin{tabular}{|c|c|c|c|c|c|c|c|}
\hline \multirow{3}{*}{ Compound } & \multicolumn{7}{|c|}{ Cell Line/LD ${ }_{50}[\mu \mathrm{M}]$} \\
\hline & \multicolumn{2}{|c|}{ HCC } & \multicolumn{3}{|c|}{ MB } & \multirow{2}{*}{$\begin{array}{l}\text { GBM } \\
\text { U251 }\end{array}$} & \multirow{2}{*}{ HUVEC } \\
\hline & HUH7 & AKH12 & DAOY & UW228-2 & D283 & & \\
\hline $10 \mathrm{a}$ & $13.94 \pm 1.02$ & $15.5 \pm 1.3$ & $16 \pm 1.12$ & $28.8 \pm 2.1$ & $17.71 \pm 1.09$ & $13.51 \pm 0.9$ & $11.58 \pm 1.11$ \\
\hline $10 \mathrm{~b}$ & $21.33 \pm 1.23$ & $23.72 \pm 1.27$ & - & - & $31.27 \pm 1.32$ & $20.44 \pm 1.58$ & $12.88 \pm 2.13$ \\
\hline $10 \mathrm{c}$ & $17.33 \pm 0.98$ & $23.27 \pm 2.1$ & $16 \pm 2.1$ & $15.74 \pm 1.32$ & $27.25 \pm 2.35$ & $21.33 \pm 1.01$ & $13.8 \pm 1.14$ \\
\hline $10 \mathrm{e}$ & $16.33 \pm 0.69$ & $32 \pm 2.21$ & $15.54 \pm 1.62$ & $26.66 \pm 1.52$ & $15.61 \pm 0.59$ & $16 \pm 2$ & $9.58 \pm 1.88$ \\
\hline $10 f$ & $24.57 \pm 1.54$ & $24.72 \pm 1.98$ & $15.77 \pm 1.09$ & $28 \pm 2.09$ & $18.78 \pm 1.22$ & $32.72 \pm 1.32$ & $17.26 \pm 2.33$ \\
\hline $10 \mathrm{~g}$ & $11.66 \pm 1.53$ & $10.18 \pm 1.09$ & $19.2 \pm 1.42$ & $12 \pm 0.99$ & $16 \pm 1$ & $11.76 \pm 1.58$ & $10.77 \pm 0.93$ \\
\hline $11 \mathrm{a}$ & $22.5 \pm 1.21$ & $28.8 \pm 1.53$ & $18.66 \pm 1.88$ & $16 \pm 1.03$ & $20 \pm 2.02$ & $18.78 \pm 2.11$ & $13.35 \pm 0.25$ \\
\hline $11 \mathrm{e}$ & $30.22 \pm 2.21$ & $28 \pm 1.39$ & $24 \pm 1.49$ & $23.46 \pm 1.56$ & $25.9 \pm 1.9$ & $23.7 \pm 1.69$ & $17.58 \pm 2.94$ \\
\hline $11 \mathrm{f}$ & $42.66 \pm 1.98$ & - & $17.33 \pm 0.99$ & $31.36 \pm 2.12$ & $29.91 \pm 1.5$ & $31.48 \pm 2$ & $22.28 \pm 1.45$ \\
\hline $11 \mathrm{~g}$ & $20 \pm 1.1$ & $28 \pm 1.72$ & $20.41 \pm 1.33$ & $20.14 \pm 1.34$ & $17.23 \pm 0.89$ & $24.8 \pm 0.92$ & $18.68 \pm 1.97$ \\
\hline $12 \mathrm{i}$ & $7.75 \pm 0.84$ & $5.75 \pm 0.47$ & $12.88 \pm 1.59$ & $28.44 \pm 2.11$ & $21.81 \pm 1.9$ & $15.33 \pm 1.59$ & $3.16 \pm 0.15$ \\
\hline $13 a$ & $13.92 \pm 0.49$ & $8 \pm 0.28$ & $19.2 \pm 1.37$ & $25.9 \pm 1.98$ & $38.4 \pm 1.11$ & $27.63 \pm 1.04$ & $12.13 \pm 0.26$ \\
\hline
\end{tabular}

\subsection{Sulfonamides and $M B$ Cell Lines}

MB is considered the most common malignant brain tumor, with an estimated $5000-8000$ cases per year worldwide [28]. Current MB classification defines four molecular subgroups, namely wingless (WNT), sonic hedgehog (SHH), group 3, and group 4 [29]. Among the MB cells tested, DAOY and UW228-2 belong to the SHH subgroup, whereas D425 corresponds to group 3. Cell line D283 exhibits features of both group 3 and group 4 [30]. Here, $50 \mu \mathrm{M}$ of compounds 10a, 10c, 10e, 10f, 10g, 11a, 11e, 11f, 11g, 12i, and 13a reduced cell viability in all 4 cell lines (Supplementary Figures S5A, S7A, S9A and S11A — data available in Supplementary Materials). Compound 10b, however, only affected D425 and D283 cells, with $\mathrm{LD}_{50}$ values of $16.38 \pm 2.34 \mu \mathrm{M}$ and $31.27 \pm 1.32 \mu \mathrm{M}$, respectively (Tables 1 and 2). $\mathrm{LDH}$ release indicative for loss of membrane integrity is shown in Supplementary Figures S5B, S7B, S9B, and S11B. Among the compounds tested, 10b, 10c, 10e, 10g, and 11e significantly reduced D425 cell viability as compared to HUVEC cells ( ${ }^{*} p \leq 0.05$, and ${ }^{* *} p \leq 0.01$; Supplementary Figure S10—data available in Supplementary Materials). The $\mathrm{LD}_{50}$ values for the designated sulfonamides in all $\mathrm{MB}$ cell lines and HUVEC cells are shown in Tables 1 and 2. LD 50 values for compounds 10c $(5.38 \mu \mathrm{M})$ and $10 \mathrm{~g}(6.61 \mu \mathrm{M})$ in D425 cells (Table 2) were slightly below the $\mathrm{LD}_{50}$ values of the above known chemotherapeutics, etoposide, and cisplatin ( 8 and $10 \mu \mathrm{M}$, respectively) reported in the study by von Bueren et al. [31]. 
Table 2. $\mathrm{LD}_{50}$ values for designated sulfonamides tested in D425 and HUVEC cells.

\begin{tabular}{cccc}
\hline \multicolumn{4}{c}{ Cell line/LD $\mathbf{L D}_{\mathbf{5 0}}[\boldsymbol{\mu M}]$} \\
\hline Compound & $\mathbf{M B}$ & HUVEC & $\begin{array}{c}\text { HUVEC/D425 } \text { LD }_{\mathbf{5 0}} \\
\text { Fold Change }\end{array}$ \\
\hline $10 \mathrm{a}$ & $16.71 \pm 2.11$ & $28 \pm 1.86$ & 1.67 \\
$10 \mathrm{~b}$ & $16.38 \pm 2.34$ & $28.9 \pm 2.97$ & 1.76 \\
$10 \mathrm{c}$ & $5.38 \pm 0.77$ & $16.77 \pm 0.71$ & 3.11 \\
$10 \mathrm{e}$ & $10.95 \pm 0.47$ & $11.54 \pm 2.8$ & 1.05 \\
$10 \mathrm{f}$ & $20.24 \pm 0.79$ & $23.15 \pm 2.21$ & 1.14 \\
$10 \mathrm{~g}$ & $6.61 \pm 1.52$ & $17.62 \pm 2.98$ & 2.66 \\
$11 \mathrm{a}$ & $21.42 \pm 0.89$ & $21.71 \pm 1.99$ & 1.01 \\
$11 \mathrm{e}$ & $17.78 \pm 1.04$ & $36.38 \pm 4.37$ & 2.04 \\
$11 \mathrm{f}$ & $32 \pm 1.37$ & $31.52 \pm 1.16$ & 0.98 \\
$11 \mathrm{~g}$ & $11.2 \pm 1.73$ & $16 \pm 2.29$ & 1.42 \\
$12 \mathrm{i}$ & $15.6 \pm 0.93$ & $8.91 \pm 2.11$ & 0.57 \\
$13 \mathrm{a}$ & $30.54 \pm 1.86$ & $16 \pm 0.79$ & 0.52 \\
\hline
\end{tabular}

\subsection{Sulfonamides and GBM Cell Line}

Despite aggressive therapy, GBM continues to be associated with a dismal prognosis in virtually all adult patients [31]. U251, a GBM cell line, was subjected to $50 \mu \mathrm{M}$ of sulfonamides. Compounds 10a, 10b, 10c, 10e, 10f, 10g, 11a, 11e, 11f, 11g, 12i, and 13a decreased cell viability by more than $50 \%$ (Supplementary Figure S13A—data available in Supplementary Materials). The LDH (lactate dehydrogenase) cytotoxicity assay was performed to assess necrotic cell death (Supplementary Figure S13B — data available in Supplementary Materials). There were no statistically significant differences in cytotoxicity between U251 cells as compared to HUVEC cells (Supplementary Figure S14-data available in Supplementary Materials). Table 1 represents the $\mathrm{LD}_{50}$ values of the tested sulfonamide on U251 and HUVEC cell lines.

\subsection{SAR Analysis}

In our previous investigations, amines derived from 2-azanorbornane were prepared and tested for antiproliferative activity using three cancer cell lines: human lung cancer A549, human colon cancer HT-29, and biphenotypic leukemia MV4-11 [21]. The selectivity was assessed with human lung microvascular endothelial cells (HLMEC) and BALB/3T3 mouse embryo fibroblasts. Bisamine compounds 8 and 9, two compounds that can be treated as reference for the current study, exhibited rather low cytotoxicity, although for compound 8 , the $\mathrm{IC}_{50}$ value for colon cancer line was comparable to cisplatin $(7.2 \pm 0.8 \mu \mathrm{M}$ vs $9.7 \pm 2.0 \mu \mathrm{M})$. The $N$-Benzyl derivative of compound 9 was more active ( $\mathrm{IC}_{50}$ values for AT549, HT-29, and MV4-11 equaled $4.1 \pm 0.1 \mu \mathrm{M}, 4.8 \pm 0.4 \mu \mathrm{M}$, and $5.4 \pm 0.7 \mu \mathrm{M}$, respectively). However, it also inhibited the growth of mouse fibroblasts $\left(\mathrm{IC}_{50}=19.7 \pm 10.1 \mu \mathrm{M}\right)$ and nonmalignant endothelial cells $\left(\mathrm{IC}_{50}=5.8 \pm 0.6 \mu \mathrm{M}\right)$, meaning its selectivity was unsatisfactory.

We planned to use compounds $\mathbf{8}$ and $\mathbf{9}$ as references in the current study. Unfortunately, they were found to be insufficiently soluble in the DMSO used for the tests. In contrast, most of the sulfonamide derivatives showed better solubility, and we could perform all tests with their samples. In our further studies, we plan to compare activities of all compounds using ethanol as the solvent.

Although the activities of the investigated sulfonamides varied from one cell line to another, certain regularities could be observed, which are important from the point of view of further developments. Comparison of activities exhibited by isomeric compounds $\mathbf{1 0}$ and 11, containing bicyclic systems of various sizes, showed that 2-azanorbornyl derivatives (in particular, 10b, 10c, 10e, and 10g) exhibited higher cytotoxicity than their 2-azabicyclo[3.2.1.]octane (bridged azepane) counterparts. The scaffold of the latter can be regarded as less rigid; on the other hand, higher flexibility of the arm containing sulfonamide moiety in 2-azabicylo[2.2.1]heptane-derived compound $\mathbf{1 0}$ seems to be of importance as well. Among substituents present in the sulfonamide, biphenyl-containing methoxy group (10e, 11e) 
or fluorine (10c) were found to be most active. For phenyl derivatives, the introduction of two $-\mathrm{CF}_{3}$ moieties resulted in enhanced activity and selectivity (compounds $\mathbf{1 0 g}, \mathbf{1 1 g}$ ), while one trifluoromethyl group in the para position was not sufficient to increase the antiproliferative properties.

Finally, dimeric species $12 \mathrm{i}$ and 13 a were not particularly active, and even their toxicity for normal cell lines was higher than for malignant ones.

\section{Conclusions}

In this study, we evaluate the effect of chiral 2-azabicycloalkane-based sulfonamides on a variety of tumor cell lines, including HCC, MB, and GBM. Our results indicate that compounds 10b, 10c, 10e, $\mathbf{1 0 g}$, and 11e notably reduce cell viability on the D425 cell line $\left({ }^{*} p \leq 0.05\right.$, and $\left.{ }^{* *} p \leq 0.01\right)$ as compared to HUVEC cells. The D425 cell line is categorized as a group 3 medulloblastoma, with high MYC proto-oncogene amplification [29]. In D425, the best discrimination in cytotoxicity between malignant and nonmalignant cells was observed for compound 10c (3.11-fold change), followed by compounds $\mathbf{1 0 g}$ and 11e (2.66- and 2.04-fold changes, respectively). Thus, compounds $10 \mathrm{c}, \mathbf{1 0 g}$, and 11e showed the highest performance among the agents tested in this study. Although the safety margin seems to be too narrow and remains far below the $>30$-fold difference recommended for safety reasons [32], appropriate modifications can be introduced to optimize the structures of the studied sulfonamides. These promising stable compounds can serve as a convenient starting point for further exploration.

Supplementary Materials: The following are available online. Figure S1: Effect of sulfonamide compounds on HUH7 cell line, Figure S2: Impact of sulfonamide compounds on HUH7 in contrast to HUVEC, Figure S3: Viability and cytotoxicity effect of sulfonamide compounds on AKH12 cells, Figure S4: Impact of sulfonamide compounds on AKH12 compared to HUVEC, Figure S5: Influence of sulfonamide compounds treatment on DAOY cell viability and cytotoxicity, Figure S6: Sulfonamide compounds sensitivity of DAOY in contrast to HUVEC cell lines, Figure S7: Effect of sulfonamides on viability of UW228-2 cell line, Figure S8: Impact of sulfonamides on UW228-2 in contrast to HUVEC, Figure S9: Sulfonamides sensitivity and cytotoxicity on D425 cells, Figure S10: Effect of sulfonamides on viability of D425 in comparison with HUVEC cell lines, Figure S11: Influence of sulfonamide compounds treatment on D283 cell viability and cytotoxicity, Figure S12: Efficacy of sulfonamides on cell viability of D283 compared to HEVEC cell lines, Figure S13: Sulfonamides and viability of U251 cells, Figure S14: Efficacy of sulfonamides on cell viability of U251 compared to HEVEC cell lines, Figure S15: X-Ray structure of bis-sulfonamide 12a, Figure S16: X-Ray structure of bis-sulfonamide 12d, Table S1: X-Ray data for compounds 12a and 12d; spectral data for new compounds and copies of ${ }^{1} \mathrm{H} N M R$ and ${ }^{13} \mathrm{C} N M R$ spectra.

Author Contributions: Conceptualization, N.R.-U. and E.W.; data curation, M.S., M.S., D.S., S.M., D.I., K.K., J.W., and A.K.; investigation, M.S., M.P., D.S., S.M., D.I., K.K., J.W., and A.K.; supervision, N.R.-U. and E.W.; writing-original draft, N.R.-U., M.S., and E.W.; writing—review and editing, D.I., K.K., and J.W. All authors have read and agreed to the published version of the manuscript.

Funding: This research received no external funding.

Acknowledgments: The authors thank Kerstin Zinober and Martha Seif for their support in cell culture experiments.

Conflicts of Interest: The authors declare no conflict of interest.

\section{References}

1. Supuran, C.T.; Casini, A.; Scozzafava, A. Protease inhibitors of the sulfonamide type: Anticancer, antiinflammatory, and antiviral agents. Med. Res. Rev. 2003, 23, 535-558. [CrossRef] [PubMed]

2. Ghorab, M.M.; Alsaid, M.S.; Al-Dosari, M.S.; El-Gazzar, M.G.; Arbab, A.H. In-Vitro Anticancer Evaluation of Some Novel Thioureido-Benzensulfonamide Derivatives. Molecules 2016, 21, 409. [CrossRef] [PubMed]

3. Ali, I.; Wani, W.A.; Saleem, K.; Hsieh, M.-F. Anticancer metallodrugs of glutamic acid sulphonamides: In silico, DNA binding, hemolysis and anticancer studies. RSC Adv. 2014, 4, 29629-29641. [CrossRef]

4. Kwon, Y.; Song, J.; Lee, H.; Kim, E.Y.; Lee, K.; Lee, S.K.; Kim, S. Design, Synthesis, and Biological Activity of Sulfonamide Analogues of Antofine and Cryptopleurine as Potent and Orally Active Antitumor Agents. J. Med. Chem. 2015, 58, 7749-7762. [CrossRef]

5. Custodio, J.M.F.; Michelini, L.J.; de Castro, M.R.C.; Vaz, W.F.; Neves, B.J.; Cravo, P.V.L.; Barreto, F.S.; Filho, M.O.M.; Perez, C.N.; Napolitano, H.B. Structural insights into a novel anticancer sulfonamide chalcone. New J. Chem. 2018, 42, 3426-3434. [CrossRef] 
6. Majellaro, M.; Stefanachi, A.; Tardia, P.; Vicenti, C.; Boccarelli, A.; Pannunzio, A.; Campanella, F.; Coluccia, M.; Denora, N.; Leonetti, F.; et al. Investigating Structural Requirements for the Antiproliferative Activity of Biphenyl Nicotinamides. ChemMedChem 2017, 12, 1380-1389. [CrossRef]

7. Meti, G.Y.; Kamble, R.R.; Kamble, A.A.; Kumbar, M.N.; Joshi, S.D.; Dixit, S.R. Synthesis and Anti-Proliferative Activity of Biphenyl Derved 5-Substituted-Indolin-2-Ones. Arch. Chem. Res. 2016, 1, 1.

8. Zhao, J.; Zhao, H.; Hall, J.A.; Brown, D.; Brandes, E.; Bazzill, J.; Grogan, P.T.; Subramanian, C.; Vielhauer, G.; Cohen, M.S.; et al. Triazole containing novobiocin and biphenyl amides as Hsp90 C-terminal inhibitors. Med. Chem. Commun. 2014, 5, 1317-1323. [CrossRef]

9. Beltageri, R.; Zhang, Y.; Zindell, R.M.; Kuzmich, D.; Kirrane, T.M.; Bentzien, J.; Cardozo, M.; Capolino, A.J.; Fadra, T.N.; Nelson, R.M.; et al. Trifluoromethyl group as a pharmacophore: Effect of replacing a $\mathrm{CF}_{3}$ group on binding and agonist activity of a glucocorticoid receptor ligand. Bioorg. Med. Chem. Lett. 2005, 15, 4761-4769. [CrossRef]

10. Kumar, B.N.P.; Mohana, K.N.; Mallesha, L.; Veeresh, B. Synthesis and in vitro antiproliferative activity of 2,5-disubstituted-1,3,4-oxadiazoles containing trifluoromethyl benzenesulfonamide moiety. Med. Chem. Res. 2014, 23, 3363-3373. [CrossRef]

11. Wojaczyńska, E.; Wojaczyński, J.; Kleniewska, K.; Dorsz, M.; Olszewski, T.K. 2-Azanorbornane-A versatile chiral aza-Diels-Alder cycloadduct: Preparation, applications in stereoselective synthesis and biological activity. Org. Biomol. Chem. 2015, 13, 6116-6148. [CrossRef] [PubMed]

12. Bailey, P.D.; Wilson, R.D.; Brown, G.R. Stereoselective synthesis of pipecolic acid derivatives using aza-Diels-Alder reactions. Tetrahedron Lett. 1989, 30, 6781-6784. [CrossRef]

13. Stella, H.; Abraham, H.; Feneau-Dupont, J.; Tinant, B.; Declercq, J.P. Asymmetric aza-Diels-Alder reaction using the chiral 1-phenyl ethyl imine of methyl glyoxylate. Tetrahedron Lett. 1990, 31, 2603-2606. [CrossRef]

14. Waldmann, H.; Braun, M. Asymmetric synthesis of bicyclic amino acid derivatives by aza-Diels-Alder reactions in aqueous solution. Liebigs Ann. 1991, 1991, 1045-1048. [CrossRef]

15. Nakano, H.; Kumagai, N.; Kabuto, C.; Matsuzaki, H.; Hongo, H. Synthesis of new chiral catalysts, $\mathrm{N}$-alkyl-2-azanorbornyl-methanols, for the enantioselective addition of diethylzinc to arylaldehydes. Tetrahedron Asymmetry 1995, 6, 1233-1236. [CrossRef]

16. Ekegren, J.K.; Modin, S.A.; Alonso, D.A.; Andersson, P.G. Multigram scale synthesis of a useful aza-Diels-Alder adduct in a one-step procedure. Tetrahedron Asymmetry 2002, 13, 447-449. [CrossRef]

17. Hashimoto, N.; Yasuda, H.; Hayashi, M.; Tanabe, Y. Aza-Diels-Alder Reaction of Methyl 2-[(R)-1-Phenylethyl] iminoethanoate with Cyclopentadiene Using Practical and Environmentally Friendly Biphasic Solvent System. Org. Process Res. Dev. 2005, 9, 105-109. [CrossRef]

18. Brandt, P.; Andersson, P.G. Exploring the Chemistry of 3-Substituted 2-Azanorbornyls in Asymmetric Catalysis. Synlett 2000, 8, 1092-1106.

19. Wojaczyńska, E.; Turowska-Tyrk, I.; Skarżewski, J. Novel chiral bridged azepanes: Stereoselective ring expansion of 2-azanorbornan-3-yl methanols. Tetrahedron 2012, 68, 7848-7854. [CrossRef]

20. Wojaczyńska, E.; Skarżewski, J. Chelating 2-azanorbornyl derivatives as effective nitrogen-nitrogen and nitrogen-chalcogen donating ligands in palladium-catalyzed asymmetric allylic alkylation. Tetrahedron Asymmetry 2008, 19, 2252-2257. [CrossRef]

21. Kamińska, K.; Wojaczyńska, E.; Wietrzyk, J.; Turlej, E.; Błażejczyk, A.; Wieczorek, R. Synthesis, structure and antiproliferative activity of chiral polyamines based on a 2-azanorbornane skeleton. Tetrahedron Asymmetry 2016, 27, 753-758. [CrossRef]

22. Wojaczyńska, E.; Skarżewski, J.; Sidorowicz, Ł.; Wieczorek, R.; Wojaczyński, J. Zinc complexes formed by 2,2'-bipyridine and 1,10-phenanthroline moieties combined with 2-azanorbornane: Modular chiral catalysts for aldol reactions. New J. Chem. 2016, 40, 9795-9805. [CrossRef]

23. CrysAlis PRO; Rigaku Oxford Diffraction Ltd: Yarnton, Oxfordshire, UK, 2017.

24. Sheldrick, G.M. Crystal structure solution and refinement with SHELXT, SHELXL. Acta Cryst. 2016, C71, 3-8.

25. Sagmeister, S.; Eisenbauer, M.; Pirker, C.; Mohr, T.; Holzmann, K.; Zwickl, H.; Bichler, C.; Kandioler, D.; Wrba, F.; Mikulits, W.; et al. New cellular tools reveal complex epithelial-mesenchymal interactions in hepatocarcinogenesis. Br. J. Cancer 2008, 99, 151-159. [CrossRef] [PubMed]

26. Rohr-Udilova, N.V.; Stolze, K.; Sagmeister, S.; Nohl, H.; Schulte-Hermann, R.; Grasl-Kraupp, B. Lipid hydroperoxides from processed dietary oils enhance growth of hepatocarcinoma cells. Mol. Nutr. Food Res. 2008, 52, 352-359. [CrossRef] 
27. Singh, A.K.; Kumar, R.; Pandey, A.K. Hepatocellular Carcinoma: Causes, Mechanism of Progression and Biomarkers. Curr. Chem. Genom. Transl. Med. 2018, 12, 9-26. [CrossRef] [PubMed]

28. Ferlay, J.; Soerjomataram, I.; Dikshit, R.; Eser, S.; Mathers, C.; Rebelo, M.; Parkin, D.M.; Forman, D.; Bray, F. Cancer incidence and mortality worldwide: Sources, methods and major patterns in GLOBOCAN 2012. Int. J. Cancer 2015, 136, 359-386. [CrossRef]

29. Ivanov, D.P.; Coyle, B.; Walker, D.A.; Grabowska, A.M. In vitro models of medulloblastoma: Choosing the right tool for the job. J. Biotechnol. 2016, 236, 10-25. [CrossRef]

30. Von Bueren, A.O.; Shalaby, T.; Oehler-Jänne, C.; Arnold, L.; Stearns, D.; Eberhart, C.G.; Arcaro, A.; Pruschy, M.; Grotzer, M.A. RNA interference-mediated c-MYC inhibition prevents cell growth and decreases sensitivity to radio- and chemotherapy in childhood medulloblastoma cells. BMC Cancer 2009, 9, 10. [CrossRef]

31. Helson, L.; Majeed, M. Pleiotropic Chemotherapy to Abrogate Glioblastoma Multiforme Migration/Invasion. Anticancer Res. 2019, 39, 3423-3427. [CrossRef]

32. Muller, P.Y.; Milton, M.N. The determination and interpretation of the therapeutic index in drug development. Nat. Rev. Drug Discov. 2012, 11, 751-761. [CrossRef] [PubMed]

Sample Availability: Samples of the compounds are available from the authors.

(C) 2020 by the authors. Licensee MDPI, Basel, Switzerland. This article is an open access article distributed under the terms and conditions of the Creative Commons Attribution (CC BY) license (http://creativecommons.org/licenses/by/4.0/). 